\title{
VISUAL DISPLAY OF RESERVOIR PARAMETERS AFFECTING ENHANCED OIL RECOVERY
}

Cooperative Agreement No:: DE-AC22-93BC14892

Contractor Name and Address: Michigan Technological University, 1400 Townsend Drive, Houghton, MI 49931-1295

Date of Report: 31 July 1996

Award Date: 29 September 1993

Anticipated Completion Date: 28 September 1996

Government Award for Current Fiscal Year: \$272,827.

Principal Investigator: James R. Wood (906) 487-2894

Project Manager: Robert E. Lemmon, Bartlesville Project Office (918) 337-4405

Reporting Period: July 1, 1996 - September 30, 1996

\section{RECEIVED}

FEB 25997

OSTI

\section{OBJECTIVE}

This project consists of two parts. In Part 1, well logs, other well data, drilling, and production data for the Pioneer Field in the southern San Joaquin Valley of California were obtained, assembled, and input to a commercial relational database manager. These data were used in PC-based geologic mapping, evaluation, and visualization software programs to produce 2-D and 3-D representations of the reservoir. Petrographic and petrophysical measurements made on samples from Pioneer Field, including core, cuttings and liquids, were used to calibrate the log suite. In Part 2, these data sets were used to develop algorithms to correlate log response to geologic and engineering measurements.

This project provides a detailed example, based on a field trial, of how to evaluate a field for EOR operations utilizing data typically available in older fields which have undergone primary development. The approach utilizes readily available, affordable PC-based computer software and analytical services. This study illustrates the steps involved in: 1) setting up a relational database to store geologic, well-log, engineering, and production data, 2) integration of data typically available for oil and gas fields with predictive modeis 


\section{DISCLAIMER}

Portions of this document may be illegible in electronic image products. Images are produced from the best available original document. 
for reservoir alteration, and 3) linking these data and models with modern computer software to provide 2-D and 3-D visualizations of the reservoir and its attributes. The techniques were demonstrated through a field trial in Pioneer Field, that produces from the Monterey Formation, a reservoir which is a candidate for thermal EOR.

\section{SUMMARY OF TECHNICAL PROGRESS BY TASK}

\section{TASK 1. PROJECT ADMINISTRATION AND MANAGEMENT}

\subsection{THE SPATIAL DATABASE MANAGER}

The Multimedia Database Management System (MDMS) has been developed in the commercial software package Toolbook. Design and implementation, which was carried out by C. Asiala, is now essentially complete. Regional location maps of southern San Joaquin Valley oil fields, structure contour maps of the Pioneer area, core photos, core data, and thin-section and SEM photomicrographs of core materials, structural cross sections through Pioneer Anticline, an atlas of photomicrographs illustrating typical diagenetic features observed in San Joaquin Valley petroleum reservoirs, elemental and spectral data collected on Fourier Transform Infrared Spectroscopy (FTIR) standards, and all quarterly reports submitted to DOE for this project were scanned into the MDMS. All data and information are accessible through drop-down menus and hotlinks in a Table of Contents. A tutorial is presented up front to guide users through the MDMS and instruct them on the various ways in which data can be viewed and retrieved. Version 1.0 of the MDMS was written to CD ROM and distributed to participants in a Technology Transfer Workshop in Bakersfield, CA, in September, 1996. Version 1.1, which contains additional information and has been reorganized for easier use, is nearing completion.

All measured and computed log curves (computed curves represent parameters such as porosity, water saturation, and clay content, which were calculated from the measured log traces using specially developed algorithms) for the $45+$ project wells on Pioneer Anticline are now in the MDMS in LAS (digital log ASCII) format, and can be exported to any commercial log evaluation program for manipulation and analysis. All log curves were written to the CD ROM in digital format.

C. Asiala developed a search engine in Microsoft Access which can be used to retrieve logs from the CD ROM. Any desired log curve can be located using queries and then exported from the CD ROM to temporary Access tables created on the computer's hard drive. Once in the Access tables, log curves can be manipulated or transferred to $\log$ evaluation packages such as GeoGraphix's QLA2 or Crocker's Petrolog program for analysis and plotting. A tutorial describing how to use the search engine was written and is now available as on-line help. 


\subsubsection{DATABASE INITIALIZATION}

Database initialization is complete.

\subsubsection{DATABASE MANAGEMENT}

All project data are managed and archived in the Multimedia Database Management System that was developed in Toolbook (see Subtask 1.1). Log evaluation is being carried out at differing levels of sophistication in the programs Pfeffer, QLA2, Crocker Petrolog, and Symbiolog. Maps and cross sections are being prepared using GeoGraphix Exploration System (GES) software. Three-dimensional visualizations were prepared in the software package MatLab.

\subsection{ORGANIZATION AND MANAGEMENT}

The management tasks continued to go smoothly this quarter.

\subsubsection{PROJECT COORDINATION}

The following trips and meetings were held this quarter:

In August and September, M. Luo and J. Allan traveled to Michigan Technological University (MTU) to work on the Pioneer project with MTU faculty and staff.

On September 24, 1996, project staff held a Technology Transfer Workshop in Bakersfield, CA. Presentations were made by J. Wood, W. Pennington, J. Allan, M. Gruener, M. Luo, W. Houston, and J. Suchoski of MTU; F. Berry and D. Olson of DPI; and R. Robinson of the California Well Sample Repository.

During the summer of 1996, graduate student W. Houston worked at Santa Fe Energy Resources in Bakersfield, CA, as a geological trainee. His summer project involved use of GeoGraphix to evaluate reservoir continuity and heterogeneity in a 130-well lease in the Kern Front Field. The skills he acquired while carrying out this project put him in a position to make important contributions to our DOE projects when he returned to MTU in the fall. His project results were released by Santa Fe for presentation at our Technology Transfer Workshop.

\subsubsection{BUDGET MANAGEMENT AND QUARTERLY REPORTS}

M. Gruener and A. Hein are responsible for daily management of the budget and expenditures. A. Hein prepares the quarterly financial reports and distributes all reports to DOE. J. Allan is responsible for quarterly and annual technical reports. 


\section{TASK 2. DATA COLLECTION}

\subsection{WELL LOGS AND WELL DATA}

DPI completed the analysis of all Pioneer project wells using their newly developed logevaluation program Symbiolog. An innovative procedure was developed for using modern $\log$ suites, calibrated to core data, to evaluate wells for which only old electric $\operatorname{logs}(\mathrm{e}-\operatorname{logs})$ are available. This procedure was used to calculate parameters such as porosity, water saturation, and clay content, which are not directly measured by these old logs. The evaluation procedure is based on an iterative process in which petrophysical data collected on core material are calibrated to $\operatorname{logs}$ in wells with full modern log suites. Porosity, water saturation, clay content, etc., are calculated from the full log suite using algorithms and then cross-checked against values measured in core. The same parameters are then calculated using only the basic electric-log suite. Algorithms are adjusted until parameters derived from the core, the full-log suite, and the e-log-only suite all show reasonable agreement within the logged interval. When an acceptable level of agreement is achieved, the algorithms can be used to calculate porosity, saturation, and lithology in old e-log-only wells.

Successful results were achieved. Porosity, saturation, and lithology were calculated for all wells in the Pioneer study area, including wells with full modern log suites, wells with intermediate-aged log suites, and wells drilled in the 1930's and 1940's for which only e$\log$ suites are available. The computed curves for all $45+$ project wells were delivered to MTU.

\subsubsection{LOG DATABASE MANAGEMENT}

All measured and computed log curves are stored in the MDMS in LAS format and are retrievable using Microsoft Access as a search engine. Log evaluation is being carried out using the programs. Pfeffer, QLA2, Crocker Petrolog, and Symbiolog. Pfeffer is a simple, inexpensive (\$290.) log-evaluation software package developed by University of Kansas researchers; QLA2 is an intermediate-level log-evaluation package suitable for general use by exploration and development geologists that is provided as a module with the GeoGraphix Exploration System; and Crocker Petrolog and Symbiolog are sophisticated log-evaluation programs suitable for use by formation-evaluation specialists.

W. Pennington is responsible for log analyses using Pfeffer and QLA2, while DPI is responsible for log evaluations using Crocker Petrolog and Symbiolog. A comparison of the different programs was presented at our Technology Transfer Workshop in order to provide attendees information that will enable them to perform a simple cost/benefit analysis and choose the software that is best fits their needs. 


\subsubsection{LOG DIGITIZATION}

Digitization of all of the well logs necessary for construction of maps and 3-D visualizations of the Miocene and Pliocene reservoirs on Pioneer Anticline is complete.

\subsection{CORE AND SAMPLE ACQUISITION}

\subsubsection{A CORE AND CUTTINGS}

Our conventional and sidewall core library of samples is complete. It consists of conventional cores and core analysis data from the UNOCAL McKittrick Front Nos. 415 and 418 wells in Cymric Field and the Tenneco 62x-30 well in Pioneer Field. Sidewall core and cuttings samples and core analysis data from the Gary Drilling, KLC 44, Well No. 375x in Pioneer Field are also in our sample library.

\subsubsection{B ARCO/UNOCAL CORE}

J. Allan arranged for the core and core data from the UNOCAL McKittrick Front Nos. 415 and 418 wells in Cymric Field to be released by UNOCAL to the California Well Sample Repository at California State University, Bakersfield for our Technology Transfer Workshop. The cores and core data from the two McKittrick Front wells are so outstanding that acquiring core data from additional wells to calibrate our logs has proved unnecessary. They were shipped to the Repository and are now in storage there. We hope to be able to arrange the eventual donation of the core and samples to the Repository, where they will reside in perpetuity and can be used as a resource by both industrial and research geologists.

\subsubsection{FLUIDS}

A data set containing over 77,000 geochemical analyses of brines recovered from wells throughout the United States was acquired from a commercial database vendor. C. Asiala designed a Microsoft Access database and archived the brine data in it.

\section{TASK 3. DATA ANALYSIS AND MEASUREMENT}

\subsection{PETROPHYSICS}

\subsubsection{POROSITY, PERMEABILITY, FORMATION FACTOR (KPF) MEASUREMENTS}

Extensive petrophysical data sets were acquired from UNOCAL for the cores from the UNOCAL McKittrick Front No. 415 and 418 wells in Cymric Field. A petrophysical data set for the Tenneco $62 \mathrm{x}-30$ well in Pioneer Field was acquired independently. 
Petrophysical data from the cores were used to calibrate the logs in these wells. The calibrations were used to analyze existing logs and produce computed logs in uncored wells which penetrate the same stratigraphic intervals on the Pioneer Anticline (see Subtask 2.1).

\subsubsection{FOURIER TRANSFORM INFRARED SPECTROSCOPY (FTIR) SPECTRA}

Current efforts concentrate on obtaining better standards for Opal A and CT. Since the FTIR work represents the M.S. thesis research project of graduate student N. Popko, it will continue after the completion of this DOE contract.

\subsection{PETROLOGY}

\subsubsection{XRD}

Xray work is essentially complete. Any additional work that is performed will be done in conjunction with Popko's FTIR work.

\subsubsection{SCANNING ELECTRON MICROSCOPY (SEM)/IMAGE ANALYSIS}

All SEM images collected to date were scanned into the MDMS. They will be available on Version 1.1 of the CD ROM.

\subsubsection{PETROLOGY}

Optical petrographic analyses are complete for 44 thin sections of the Monterey reservoir in our cored wells. Results include petrographic descriptions, $35 \mathrm{~mm}$ slides, and $35 \mathrm{~mm}$ prints of thin sections which are characteristic of each lithologic type. All photomicrographs and thin section descriptions were scanned into the MDMS.

An atlas of thin section petrology of representative reservoir samples from the southern San Joaquin Basin was acquired for the project. The atlas was compiled by $M$. Hayes at Chevron Research under the direction of J. Wood in 1988. The atlas, which consists of several hundred described and interpreted photomicrographs from many fields, emphasizes diagenetic alteration. The photomicrographs and their captions were scanned into the MDMS.

\subsection{LOG CALIBRATION}

Log calibration is complete.

\subsubsection{DATA PREPARATION}

Data preparation is complete. 
D. Crane of DPI picked the tops of the Etchegoin Formation, the Monterey Formation, the Reef Ridge Sand, and the Reef Ridge Shale, in all project wells, and constructed faultplane maps for all faults in the vicinity of Pioneer Field. The data were used by M. Luo to construct 3-dimensional visualizations of the Pioneer Anticline in MatLab. The results of his 3-D visualizations, with "slice and dice" capability, are quite impressive, and were presented at our Technology Transfer Workshop.

\subsubsection{MODEL SELECTION}

Final analysis of all well logs from all Pioneer project wells was completed using the program Symbiolog, developed by log analysts and programmers at DPI. Symbiolog uses a newly developed technique called multi-facies zone summation analysis. Conventional $\log$ analysis packages apply one set of cutoffs (porosity, residual water saturation, etc.) to a reservoir. Multi-facies zone summation analysis allows the user to define different facies within a reservoir and to assign a different cutoff value to each facies. Expected production within a heterogeneous reservoir can be estimated much more precisely this way than with the conventional approach.

Customized parameter tables were developed from core data and modern log suites for use in special algorithms that compute lithology, \% clay, \% shale, matrix type, porosity, and $S_{\mathrm{W}}$ from old electric-log data and plot the results in $\log$ form. These calculations were performed on all $45+$ Pioneer project wells and computed curves were generated.

\section{TASK 4. MODELING}

\subsection{GEOCHEMICAL MODELING}

The geochemical modeling program CHILLER was used by J. Suchoski to model fluidrock interaction. This has very practical significance because of active steamflooding of the Monterey and Etchegoin Formations elsewhere in the southern San Joaquin Valley.

\subsubsection{GEOCHEMICAL MASS TRANSFER}

Geochemical mass transfer work using CHILLER was also performed by J. Suchoski.

\subsubsection{THERMODYNAMIC DATABASE}

Two databases were used. The thermodynamic database SOLTHERM contains thermodynamic information on fluid species, gases, and minerals. Over 400 species are contained in the database. The data are valid over a temperature range of $0^{\circ} \mathrm{C}$ to $300^{\circ} \mathrm{C}$. The database containing information on oxygen isotopes, OXYBASE, is complete. 


\subsection{BASIN MODELING}

Basin modeling work on fluid flow out of the deep San Joaquin Basin continued. M. Luo developed a number of new applications for constructing 3-D surface and volume visualizations and pseudo-seismic cross sections using the program MatLab. These new applications were demonstrated at the Technology Transfer Workshop using data from Pioneer Anticline.

\subsubsection{GEOHISTORY}

A. Nigrini's one-dimensional basin modeling effort using the program BasinMod, which focused on analysis of the Elk Hills 934-29R well in the Naval Petroleum Reserve, the deepest well $(24,442$ feet) in the San Joaquin Valley, is complete. Results were presented in a talk and poster display at the Technology Transfer Workshop.

\subsubsection{2-D AND 3-D FIELD VISUALIZATIONS AND BASIN MODELS}

MatLab 3-D Visualizations: 3-D visualizations of the Pioneer Anticline continue to be developed in MatLab. This commercially available statistics and visualization package is both flexible and powerful and can easily perform both 3-D surface and 3-D volume visualizations. M. Luo loaded the formation-top and fault-trace data assembled by D. Crane of DPI into MatLab and constructed excellent 3-D surface and volume visualizations, which can be rotated to any orientation and sliced at any angle for viewing. He added the capability to map accurate fault intersections on formation-top contour maps and project fault planes in 3 dimensions at any dip angle desired. Results were presented at the Technology Transfer Workshop.

B. Wei is continuing to use MatLab to produce "pseudo-seismic" sections from SP and gamma ray-logs. Using Wei's program individual pseudo-seismic logs (log traces whose amplitudes have been color-coded to resemble seismic amplitude traces) can easily be selected from a map-view window and then displayed as well-log or pseudo-seismic cross sections.

ER Mapper - J. Suchoski is developing our ability to use ER Mapper, Version 5.0, to input and output several types of graphics files to GeoGraphix. ER Mapper is a module that provides the GES with Geographic Information System (GIS) capabilities. We intend to import aerial and satellite photos into GeoGraphix, where we can overlay surface maps and surface data (roads, surface facilities, etc.) on the photographic images. 


\section{TASK 5. TECHNOLOGY TRANSFER}

\subsection{REPORTS}

A CD ROM, which contains the MDMS with all project data, maps, cross sections, interpretations, and reports, was distributed to Technology Transfer Workshop participants in September. A. Nigrini is currently preparing a paper on the BasinMod study of the deepest well in the San Joaquin Valley for publication.

\subsection{MEETINGS AND WORKSHOPS}

\section{Technology Transfer Workshop}

A Technology Transfer Workshop was held in the Walter Stern Library Building and at the California Well Sample Repository at California State University, Bakersfield on September 24, 1996. R. Robinson, the Director of the Repository, was instrumental in planning and arranging the event. Twenty two participants from major oil companies, independents, government agencies, and the oil and gas consulting community attended.

The Workshop included a core display and barbecue at the Repository. Cores from the McKittrick Front calibration wells (including portions of the 700-ft research core from the McKittrick Front 418 well) were on display, along with core from selected intervals in the Elk Hills $934-29 \mathrm{R}$ well that was used in our Geohistory modeling study. Poster displays accompanied the cores. All participants received a workshop notebook which summarized project results and Version 1.0 of the MDMS CD ROM. 